\title{
IMPACT OF RENUTRITION MILK ON THE IMPROVEMENT of Clinical Profile and Gut Microbiota of MALNOURISHED CHILDREN
}

\author{
Asmaa Belgharbi ${ }^{1}$, Aicha Tir Touil Meddah ${ }^{1}$, Boumediene Meddah $^{1},{ }^{2}$ Catherine \\ Mullié and Mokhtar Nehhal ${ }^{3}$ \\ ${ }^{1}$ Laboratory of Bioconversion, Engineering Microbiological and Safety Health, Faculty \\ of Natural and Life Sciences, University of Mustapha Stambouli of Mascara, Mascara, \\ 29000, Algeria \\ ${ }^{2}$ Laboratory of Glycochemical, Antimicrobiens and Agro-resources, Amiens, 80080, \\ France \\ ${ }^{3}$ Service of pediatric, EPH Meslem Tayeb, Mascara, 29000, Algeria \\ asmaabelgharbi@yahoo.fr
}

(Received July 2019 - Accepted May 2020)

\section{ABSTRACT}

Belgharbi, A., Tir Touil Meddah, A., Meddah, B., Mullié, C., \& Nehhal, M., (2020). Impact of renutrition milk on the improvement of clinical profile and gut microbiota of malnourished children. Lebanese Science Journal, 21(1), 12-23.

Childhood malnutrition is a severe disease that kills 3.1 million children under the age of five worldwide yearly. Our objectives are to compare the clinical profile and the intestinal microbiota of malnourished children and healthy ones residing in the city of Mascara (Algeria), and to specify the impact of the administration of renutrition milk on the improvement of their gut microbiota. 40 children in total, aged between 2 and 36 months were chosen for this study. A clinical examination and a microbiological analysis of fecal matter were performed. The first results showed that the malnourished children included in the study suffer from severe malnutrition characterized by stunting and remarkable underweight and that their intestinal flora is quantitatively and qualitatively different from that of healthy children. Moreover; the administration of the renutrition milk has a positive influence on the composition of the intestinal flora in these malnourished children.

Keywords: Children malnutrition, renutrition milk, intestinal microbiota, clinical profile.

\section{INTRODUCTION}

Malnutrition is the cause of the death of 3 to 5 million children every year; however, it is rarely listed as the direct cause of these deaths. This is probably due to the complexity and diversity of the causes involved and the consequences on the viable functions of children (Saunders et al., 2015). 
The human gut microbiota is the focus of one of the most dynamic research fields in our time, it has always been considered as a separate organ whose beneficial and indispensable effects are highly discussed (Le Blanc et al., 2013; Magnúsdóttir \& Thiele, 2018).

Moreover, many studies have illustrated associations between several metabolic diseases and gut microbiota (Turnbaugh et al., 2006; Dicksved et al., 2008).

Thus, it has been found that malnutrition can delay the normal development of intestinal flora in childhood or induce a modified composition that does not provide the symbiotic functions necessary for healthy growth (Million et al., 2017; Kumar et al., 2018).

This led us to evaluate the clinical and nutritional status of malnourished children, to compare the diversity of their intestinal flora with that of healthy children and to illustrate the impact of introduction of renutrition milk on the improvement of the composition of this flora.

\section{MATERIALS AND METHODS}

\section{Protocol of the clinical study}

It is a case-control comparative study, consisting of two groups of 20 children each, aged 2 to 36 months residing in the Mascara region, one of malnourished children, the other of healthy ones. The trials were conducted in accordance with declaration of Helsinki (Council for international organizations of medical sciences, 1982).

A prior agreement was obtained from the officials of the health facility Meslem Tayeb in which the children were recruited as subjects. Informed parental consent was obtained for ethical reason. Moreover, the pediatrician's declaration of honor for their participation to the study was designed according to the Belgian guideline's law of 8 December 1992 (Keuleneer \& Lontings, 1993).

\section{Inclusion criteria}

Patients will be included in the study if they are:

- Suffering from proteo-energetique malnutrition disease.

- Aged between 2 and 36 months

- Are not on antibiotic therapy or corticosteroid treatment.

- Feeding by the same commercial baby milk (Table 1). 
Table 1. The biochemical composition of the two types of milk selected for study.

\begin{tabular}{|l|l|l|}
\hline Compounds & $\begin{array}{l}\text { Commercial dietary milk } \\
\text { (for 100g) }\end{array}$ & $\begin{array}{l}\text { Renutrition milk } \\
\text { (for 100g) }\end{array}$ \\
\hline Energy (Kcal) & 485 & 100 \\
\hline Protein (g) & 16 & 2.9 \\
\hline Lactose (g) & 55.4 & 4.2 \\
\hline Potassium & $744 \mathrm{mg}$ & $5.9 \mathrm{mmol}$ \\
\hline Sodium & $231 \mathrm{mg}$ & $1.9 \mathrm{mmol}$ \\
\hline Magnésium & $655 \mathrm{mg}$ & $0.73 \mathrm{mmol}$ \\
\hline Zinc (mg) & 3.7 & 2.3 \\
\hline copper (mg) & 300 & 0.25 \\
\hline
\end{tabular}

\section{Sampling mode}

The simple random sampling (EAS) method was used to form the two groups of the study from a cohort of malnourished children and children with adequate nutritional status. The test group (TG) includes 20 malnourished children fed with commercial baby milk. The control group (CG) consisted of 20 healthy children receiving the same commercial baby milk as children described as malnourished cases for a total of 60 days.

Indeed, the children of TG are treated with nutritional rehabilitation milk called "renutrition milk" for a period of 30 days after administration (Figure 1); to evaluate its capacity to improve the clinical profile of these children.

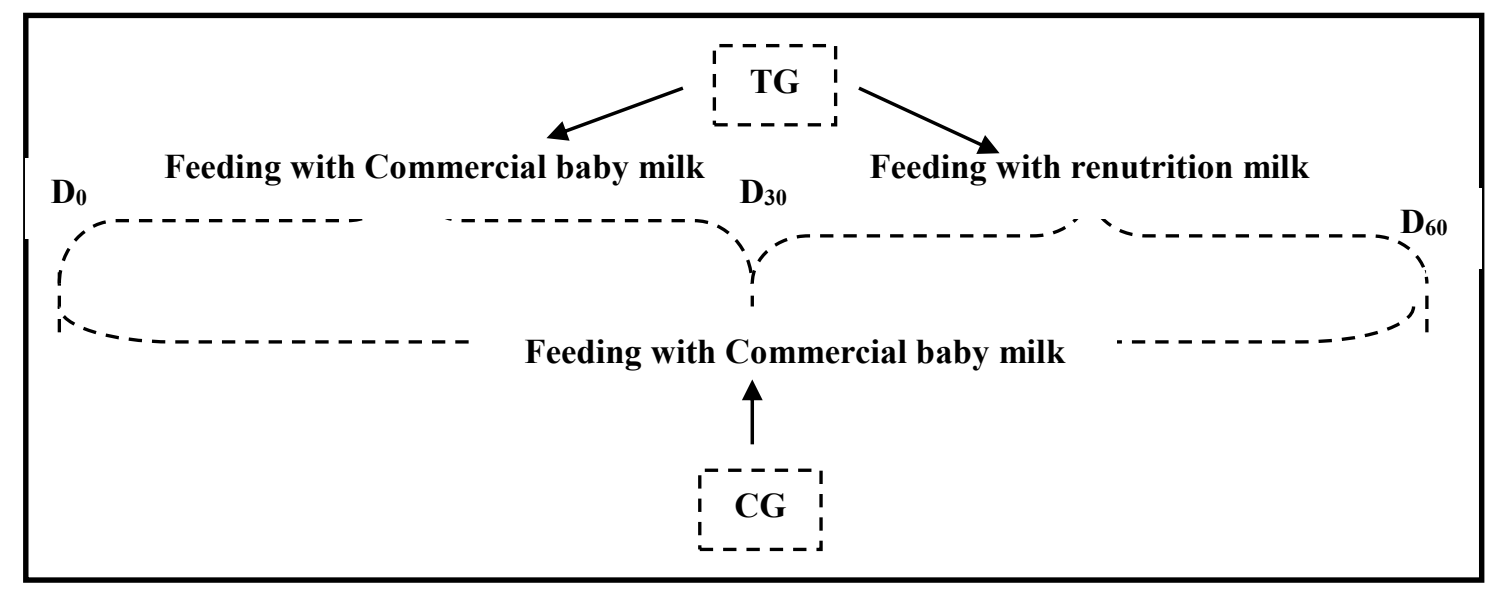

Figure 1. Illustrative diagram of the experimental sampling mode.

The use of this treatment for proteo-energetic malnutrition is due according to WHO and Unicef recommendations (2007), as well as, to the positive results get by many studies such as Simmer et al., (1988), Briend (2003), Diop et al., (2003), and Kaguamba \& Kebaabetswe (2018) (Table 2). 
Table 2. Renutrition milk formula (g/ml).

\begin{tabular}{|l|l|}
\hline Compounds & \\
\hline Sugar(g) & 50 \\
\hline Skrim powder milk (g) & 80 \\
\hline Mineral mixture(ml) & 20 \\
\hline Vegetable oil (g) & 60 \\
\hline Vitamin complex (mg) & 140 \\
\hline Boiled water ml) & 1000 \\
\hline
\end{tabular}

\section{Selection criteria of malnourished children}

In General, malnutrition is defined as an imbalance between nutrient intake and the body's needs. Which includes stunting (low height/age ratio), emaciation (low weight/height ratio), underweight (low weight/age ratio) and micronutrient deficiencies (essential vitamins and minerals). It can be measured by different ways; in our study, we were interested in the recommendations of World Health Organization [WHO] (2017). Indeed, we used the $\mathrm{Z}$ score (Table 3) and the measurement of Brachial perimeter (BP) /Cranial perimeters (CP) according to Waterlow et al., (1977), and Bovet et al., (2011).

Table 3. Growth references $\mathrm{Z}$ score (WHO, 2017).

\begin{tabular}{|l|l|}
\hline $\mathbf{Z}$ score & Nutritional Status \\
\hline$<-2.5$ & Severe acute malnutrition (MAS) \\
\hline$\geq-3$ à $<-2$ & Moderate acute malnutrition (MAM) \\
\hline$\geq-2$ à $<+1$ & normal nutritional status \\
\hline$\geq+1$ à $<+2$ & Overweight \\
\hline$\geq+2$ & Obesity \\
\hline
\end{tabular}

\section{The mode of clinical data collection}

The weight of the undressed child is measured using a baby scale model SECA (TERRAILLON, France) with an accuracy of $0.005 \mathrm{~kg}$ (for children under 2 years old) and a weigh scale 750 model Viva-SECA (TERRAILLON, France) with an accuracy of $0.100 \mathrm{~kg}$ (for children from 2 to 3 years). The length size, the brachial and cranial perimeters were determined in a supine position using a measuring board and measuring tape respectively.

The main parameters studied are:

* Evaluation of the health and nutritional status of children (CG and GT) through the expression of anthropometric parameters in nutritional evaluation curves (Z-score) (Rolland-Cachera, 1991).

* Monitoring the improvement of the nutritional status of TG children over time (after administration of the renutrition milk) via the determination of the weight Delta $((\Delta \mathrm{P})$ in $\mathrm{kg})$ according to the formula of Ashworth et al. (2003).

Daily gain in weight $(\mathrm{g} / \mathrm{kg} / \mathrm{day})=\Delta \mathrm{P} \times 1000$ / (residence time $\mathrm{x}$ initial weight) 


\section{Microbiological study protocol}

Given the unfeasible of access to the intestinal flora, fecal flora has been targeted since it reflects that which is upstream of the rectum (Marteau et al., 2001). As a result, stool collections from both groups was performed from the children's diapers using a sterile spatula and placed in sterile jars for this study. These samples are transported to the analysis laboratory at a temperature of $+4{ }^{\circ} \mathrm{C}$ and were analyzed within a maximum of 12 hours after sampling.

\section{Research, isolation and identification of germs.}

$1 \mathrm{~g}$ of stool is put into a sterile vial containing $9 \mathrm{ml}$ of sterile physiological water $(0.9 \%)$. This mixture is homogenized by agitation in a vortex; to get the first dilution $\left(10^{-}\right.$ $\left.{ }^{1}\right)$. Microbiological analyses are carried out on dilutions obtained from this one.

The characterization of the intestinal flora was carried out according to the following steps:

* Microscopic examinations (after staining with Lugol reagent and Gram stain of faecal smears). (Gossling \& Slack, 1974)

* Research, enumeration and identification of the main cultivable elements of the fecal microbiota:

Total Aerobic Mesophilic was isolated on Nutrient agar, Enterobacteria on Hecktoen agar and Eosin Methylene Blue agar (EMB agar), Enterococcus sp were isolated on Bile Esculin Azide agar (BEA agar), Staphylococcus $s p$ on Chapman agar. All these cultures were incubated in aerobic conditions at $37^{\circ} \mathrm{C}$ for $48 \mathrm{~h}$.

Clostridium sulphito-reducers on the $V F$ agar were supplemented with $0.5 \mathrm{ml}$ of sodium sulfate and some drops of iron alum, after incubation in anaerobic conditions at $37^{\circ} \mathrm{C}$ for $72 \mathrm{~h}$. Lactic acid bacteria (Lactobacillus and Bifidobacterium) were isolated in Man, Rogosa and Sharpe agar (MRS agar) supplemented with 0,05\% cysteine and incubated 18 hours a day at $37^{\circ} \mathrm{C}$ in anaerobiosis) and yeasts (agar extract of Malt incubated at $37^{\circ} \mathrm{C}$ for 2 to 5 days) (Marteau et al., 2001).

The enumeration of germs was made on the dishes presenting between 30 and 300 colonies and expressed in log colony forming units (CFU) per gram of fecal sample, by the following formula (Beraud, 2001).

$$
\log \mathrm{CFU} / \mathrm{g}=\log \frac{\text { number of colony }}{\text { dilution } * \text { wolume seeded }}
$$

The identification of colonies found in each culture medium was confirmed by the use of biochemical tests (Beraud, 2001).

\section{Statistical analysis.}

*All these measurements and determinations were made in triplicate and the results obtained were expressed as mean \pm standard deviation. These were the object of a statistical analysis of the variance (Anova test), whose difference is considered significant if the $p<0.05$. 


\section{RESULTS}

Assessment of health and nutritional status.

The anthropometric measurements obtained in the two groups are shown in Table 4.

\begin{tabular}{|c|c|c|c|c|c|}
\hline Parameters & CG (at Do) & CG ( at D60) & TG ( at $\left.D_{0}\right)$ & TG (at D30) & $\begin{array}{l}\text { TG ( at D } 60 \text { ) } \\
\text { (After administration of } \\
\text { renutritionel milk) }\end{array}$ \\
\hline Age (months) & \multicolumn{2}{|l|}{$19,95 \pm 9,28$} & \multicolumn{3}{|l|}{$19,05 \pm 9,28$} \\
\hline Weight (kg) & $11,6 \pm 3,34^{*}$ & $12,4 \pm 2,03$ & $7,53 \pm 1,94^{*}$ & $9,53 \pm 0,63$ & $10,22 \pm 0,04^{*}$ \\
\hline Length (m) & $0,73 \pm 0,08$ & $0,76 \pm 0,11$ & $0,59 \pm 7,96$ & $0,62 \pm 3,16$ & $0,64 \pm 1,02$ \\
\hline $\begin{array}{l}\text { Cranial perimeter } \\
(\mathrm{CP})(\mathrm{cm})\end{array}$ & $46,1 \pm 3,28$ & $47,1 \pm 2,28$ & $49,01 \pm 3,56$ & $49,21 \pm 2,56$ & $49,23 \pm 0,78$ \\
\hline $\begin{array}{l}\text { Brachial perimeter } \\
(B P)(\mathrm{cm})\end{array}$ & $15,4 \pm 2,83$ & $16,01 \pm 1,56$ & $9,55 \pm 2,30$ & $9,61 \pm 3,52^{*}$ & $14,87 \pm 3,46^{*}$ \\
\hline Report BP/CP & $0,33 \pm 0,04$ & $0,33 \pm 0,10$ & $0,19 \pm 0,04$ & $0,19 \pm 0,51^{*}$ & $0,30 \pm 0,46^{*}$ \\
\hline Sex Ratio & \multicolumn{2}{|l|}{0,66} & \multicolumn{3}{|l|}{0,66} \\
\hline
\end{tabular}

Table 4. Results of the anthropometric data of the two groups of children.

These anthropometric data allowed the assessment of the growth status of these children using software developed by the World Health Organization (WHO), called "W.H.O Anthro" (Figure 2).

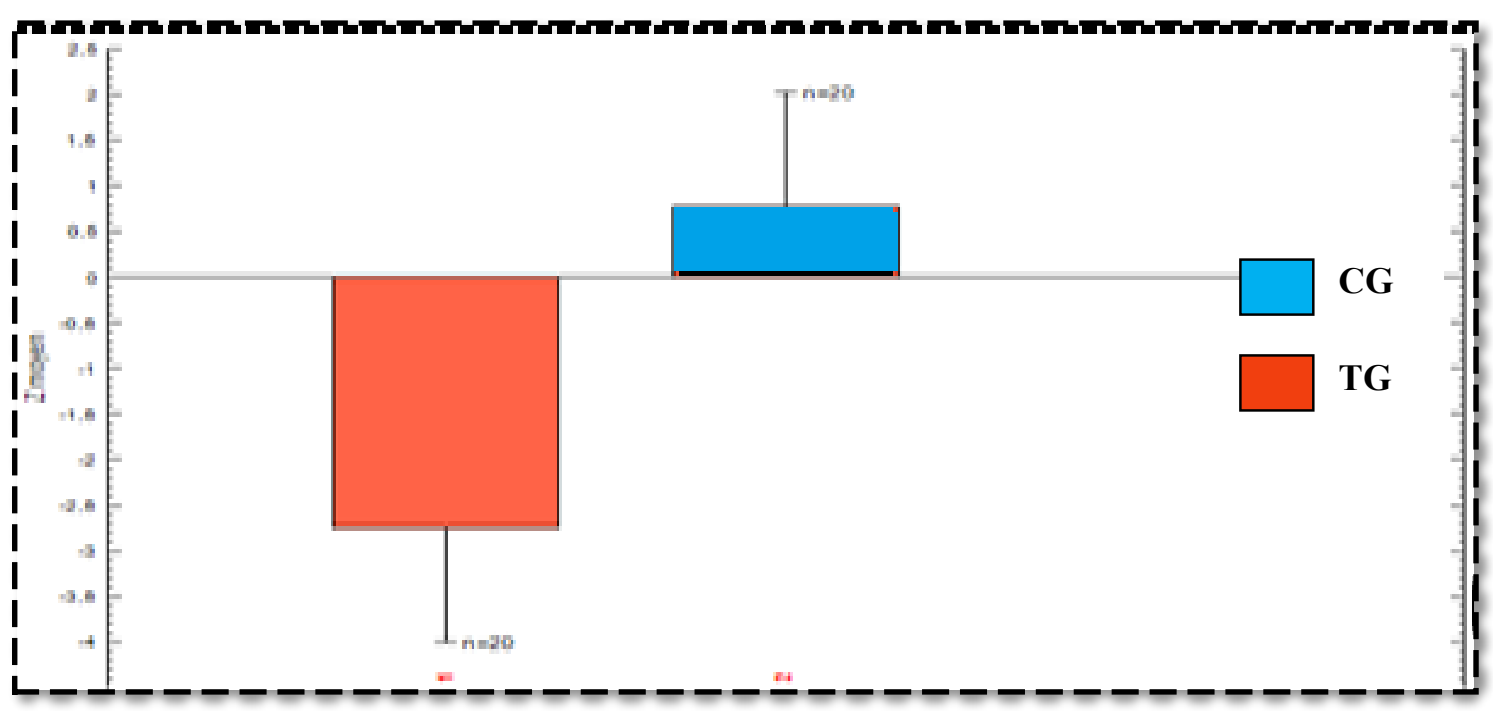

Figure 2. Results of the nutrition survey (weight for age) in $Z$ score two study groups according to "WHO anthro". 


\section{Monitoring the nutritional status of malnourished children after intervention}

During the introduction phase of commercial baby milk $\left(\mathrm{D}_{0}-\mathrm{D}_{30}\right)$, a loss continues to occur for TG, unlike CG children (Figure3). However; the introduction of renutrition milk between $\mathrm{D}_{30}$ and $\mathrm{D}_{60}$ leads to a positive mean weight gain $(2.006 \pm 2.03 \mathrm{~g} / \mathrm{kg} / \mathrm{d})$.

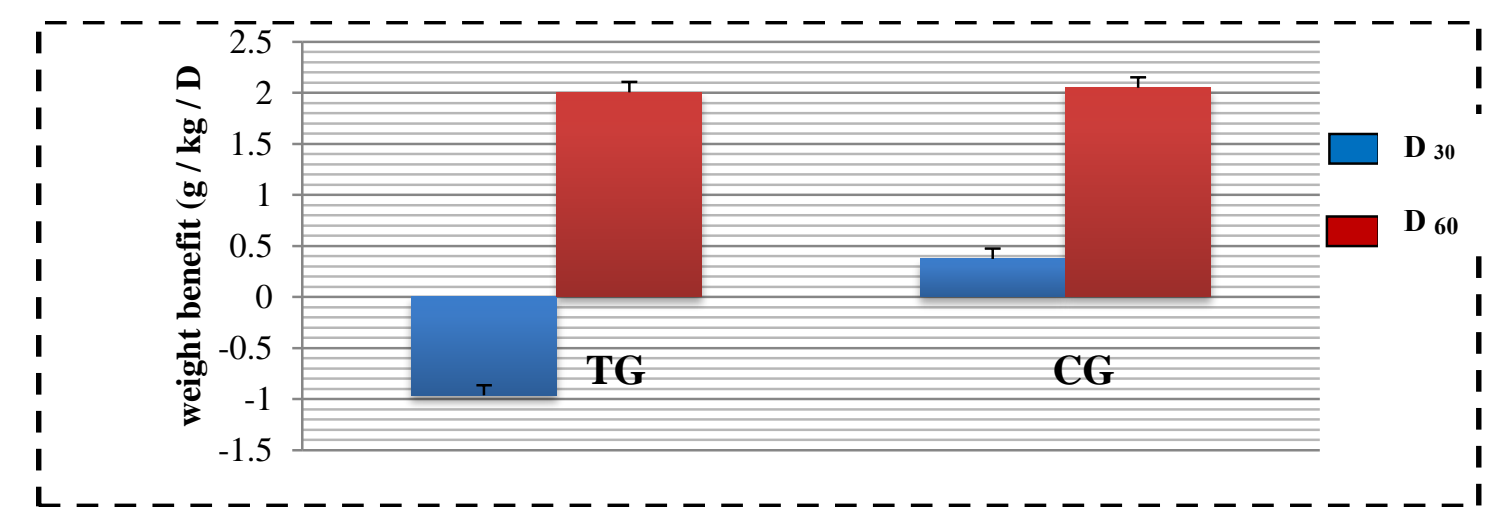

Figure 3 . Variation of weight gain in both groups of children according to the period.

Characterization of the fecal microflora

Microscopic examination (Lugol and Gram Staining) (Figure 4)

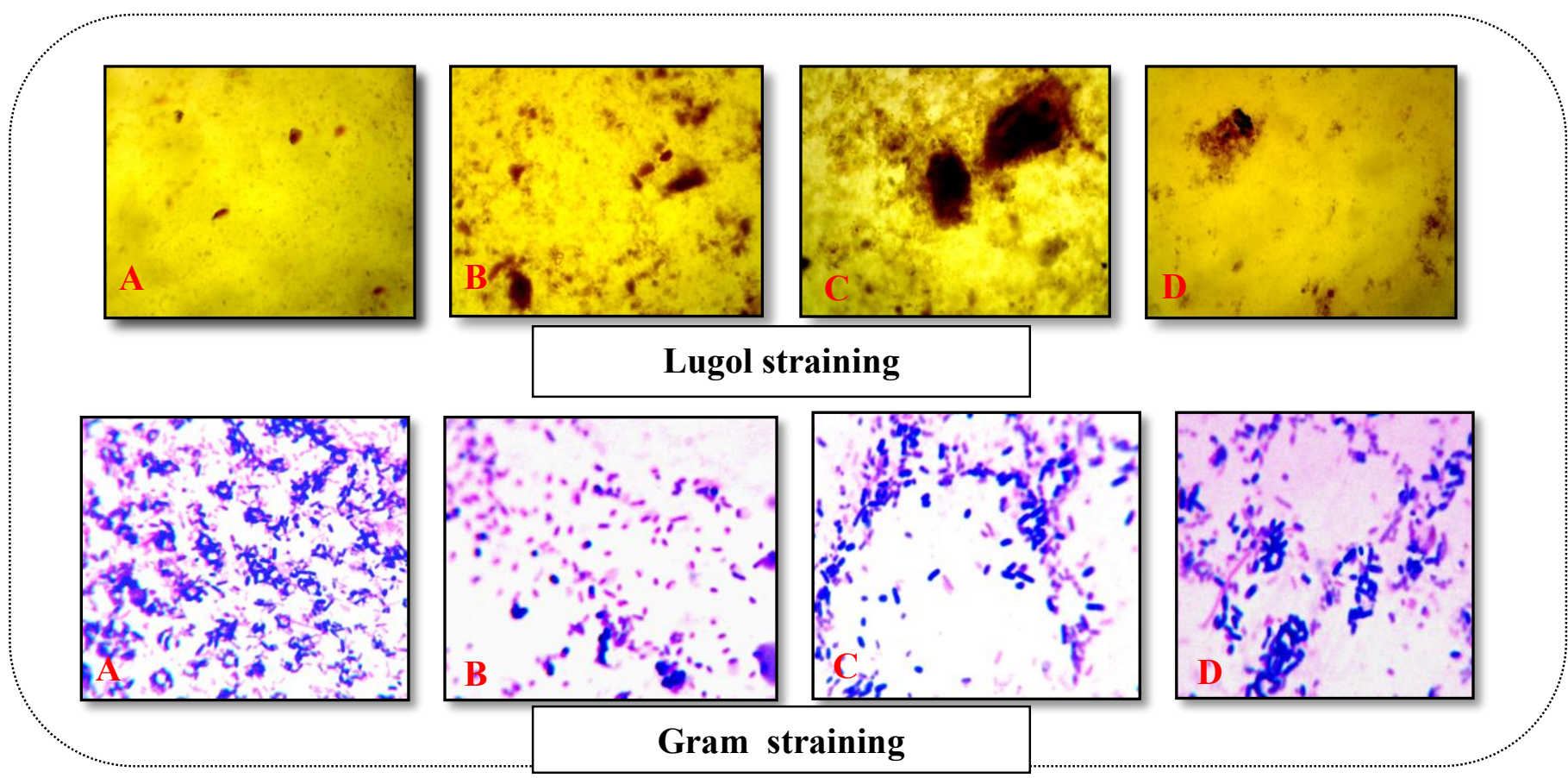

A: $C G, B: T G$ at $D_{0}, C: T G$ at $D_{30}, D: T G$ at $D_{60}$

Figure 4. Visualization of starch grains undigested after Lugol staining (X 400) and the diversity of the intestinal microbiota after the Gram strain of fecal (X 1000 with immersion oil). 
Figure 4 shows the presence of starch grains of varying size and abundance from one sample to another depending to the clinical condition of the child. However, the Gram staining results of fecal smears of healthy and malnourished children illustrate a variation of the ratio between Gram-negative and Gram-positive bacteria.

\section{Enumeration by culture and identification of the main microorganisms composing the intestinal microbiota}

A remarkable decrease in the microbiota of malnourished children in comparison with the control group was observed (6.73 \pm 0.51 for CG VS $4.85 \pm 1.44$ for TG). In TG, this flora is dominated by Enterobacteria whose main isolate species are: Escherichia coli, Shigella flexneri, Salmonella cholera suis, Klebsiella pneumonia and Citobacter amalonticus, followed by the genus Staphylococcus whose main isolated species were Staphylococcus aureus and Staphylococcus saprophyticus. The main species of these two genera isolated from CG children were: Escherichia coli, Proteus vulgaris, Enterobacter cloacae, Staphylococcus epidermis and Staphylococcus saprophyticus.

In contrast, the genera Enterococcus, Clostridium, lactobacillus are poorly represented in malnourished children compared to healthy one throughout the study (Figure 5).

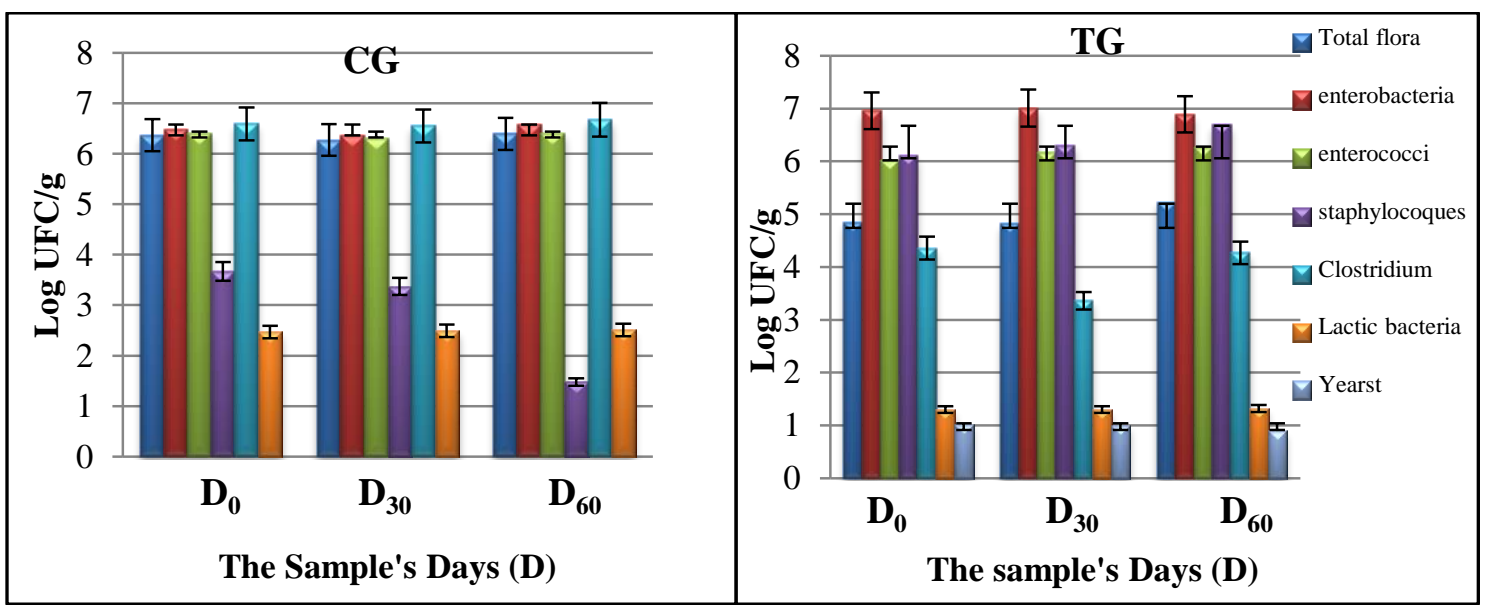

Figure 5. Composition of fecal microflora in the two study groups.

\section{DISCUSSION}

The first anthropometric results allow us to collect very important information about the clinical and nutritional status of our groups, note that:

- The $\mathrm{Z}$ score shows that the $\mathrm{CG}$ is situated in the " Medium Zone " with a Z score value between 0.5 and 2 standard deviations (SD) (Figure 2), that means a normal body development, according to Waterlow et al., (1977). And that the TG have a higher abundance of underweight and the growth retardation, since their $\mathrm{Z}$ score is globally between (-0.5) to (-2.5) SD (Figure 2).

Note that the child is then said to be moderately malnourished if his $\mathrm{Z}$ score is below 
two standard deviations $(<-2)$ (Waterlow et al., 1977).

- $\mathrm{BP} / \mathrm{CP}$ ratio in the CG meets perfectly the standard classification of Mac-LarenKanawati (for a $\mathrm{BP} / \mathrm{CP} \geq 0.31$ ), but the TG had an average $\mathrm{PB} / \mathrm{PC}$ ratio of 0,23 $\pm 0,03$ (Table 4), that means the presence of the several malnutrition (several malnutrition $=$ the ratio $\mathrm{PB} / \mathrm{PC}$ is lower than 0,30 ) (Waterlow et al., 1977).

The monitoring of the nutritional status of malnourished children after intervention shows that the introduction of renutrition milk between $\mathrm{D}_{30}$ and $\mathrm{D}_{60}$ leads to a positive mean weight gain $(2.006 \pm 2.03 \mathrm{~g} / \mathrm{kg} / \mathrm{d})$ which resembles the norms of WHO for the weight gain of an elderly child one year in normal growth $(\geq 1 \mathrm{~g} / \mathrm{kg} /$ day) (WHO, 2000), but it always insufficient gain for malnourished child in rehabilitation phase (which must be equal to $20 \mathrm{~g} / \mathrm{kg} /$ day) (WHO, 2000).

For the microbiological results, the microscopic examination of the fecal microbiota shows that:

1. Lugol staining illustrates a significatif different of the size of starch grains:

- In CG, a small amount of starch grains of very small size is observed. This reflects an almost complete digestion by salivary and intestinal amylases which are partially immature (full maturity is reached at the age of 3 years) but active from birth (Gobert et al., 2004).

- In the TG, a dominance of large starch particles appearing in dark brown is noted at $\mathrm{D}_{0}, \mathrm{D}_{30}$ (Figure 4). Children belonging to our group defined as "malnourished" do not seem able to digest the starch contained in the food ration. This could be due to a deficiency of digestion functions, especially complex sugars in the case of amylase, and absorption in these children and / or a defect in the composition of the intestinal flora that can participate in the digestion of starch in the intestinal lumen. In fact, intestinal malabsorption revealed by clinical examination is mainly related to intestinal atrophy that has been observed previously. However, the reduction in the amount of starch grains in the stools is observed visually on $\mathrm{D}_{60}$, can illustrate the positive effect of renutrition milk.

2. The Gram staining results of fecal smears, shows the difference of Gramnegative and Gram-positive bacteria ratio between the two groups:

- In CG: $1 / 3$ of Gram-negative bacilli and 2/3 of Gram-positive coccobacillus cocci are found. This finding is consistent with the results of the work done by Lagier et al., (2012).

- For TG, a predominance of Gram-negative bacilli is visualized when using commercial milk (at $\mathrm{D}_{0}$ and $\mathrm{D}_{30}$ ) with a fairly low rate of gram-positive bacteria. This explains the origin of frequent diarrhea in these children resulting from an exaggerated proliferation of iodophilic flora (Gram negative) following an acceleration of the colon transit (Lagier et al., 2012). Nevertheless, there is a return to the equilibrium intestinal microbiota on $\mathrm{D}_{60}$ with an increase in the rate of Gram-positive bacteria that generates a Gram-negative / Gram-positive ratio similar to that observed in healthy children. 
Moreover, the enumeration of the gut microbiota shows that the remarkable decrease in the microbiota of malnourished children can be explained by the effect of malnutrition that causes an atrophy of mucous membranes and intestinal villi which are very important for the adhesion and installation of intestinal microflora (ThompsonChagoyán et al., 2007). In fact, the desquamation of the intestinal villi and the abundance of mucus cause the atrophy of the specific carbohydrate receptors present in the glycocalyx.

In addition; the low rate of the genera Enterococcus, Clostridium, lactobacillus in malnourished children may be explained by the fact that these bacteria adhere strongly to the intestinal mucosa, and following the acceleration of transit, the colonization of the digestive tract by these microorganisms is weak (Kolling et al., 2012).

Indeed; the yeast Candida albicans is the only isolated yeast stool of both groups because, is considered as the normal intestinal microflora, but the risk of long-term colonization is exacerbated by malnutrition, which affects the development of the intestinal epithelium (Lagier et al., 2012). Finally, these results confirm the new concept of " the intestinal microbiota maturity" recently established by Subramanian et al. (2014) who suggest that even after a therapeutic and nutritional intervention, the intestinal flora is not totally restored and remains "immature". However, a significant difference was found between the three sampling times. This indicates that the change in commercial milk and the introduction of renutrition milk have a significant positive influence on the development of the intestinal flora of malnourished children.

\section{CONCLUSION}

The results show that the malnourished children included in the study suffer from severe malnutrition characterized by stunting and remarkable underweight. Their intestinal flora is quantitatively and qualitatively different from that of healthy children with a dominance of Staphylococcus aureus, Candida albicans and Enterobacteria, while total flora and other genera such as Enterococcus sp., Clostridium sp., Lactobacillus sp. and Bifidobacterium sp. are less present. Treatment with renutrition milk, although it has a benefit in terms of weight gain in malnourished children, has a significant effect on the composition of the microbiota.

As with the majority of case studies, our research is subject to some important limitations:

The first is that, our study focused on young children (between 2 and 36 months) since they are most affected by protein-energetic malnutrition, which is the first limit for our study, because at this young age, the intestinal flora is not yet stable, so these results can't be generalized to the wider population.

The second limitation concerns the difficulty to replicate this study because it is very difficult to track the evolution of the clinical profile of these children, in fact, most of them leave the hospital after their recovery; makes it very difficult to find them and continues the studies (that's why we limited our TG to 20 children who were followed for 60 days completely) 
The third one is that the use of fecal flora in our examination can't represent all the existing microbiota in the gut., in fact more than $75 \%$ of the intestinal flora is not cultivable in the laboratory

\section{REFERENCES}

Ashworth, A., Khanum, S., Jackson, A., \& Schofield, C. (2003). Guidelines for the inpatient treatment of severely malnourished children. World Health Organization. http://www.Who.int,guide_inpatient_text

Beraud, J. (2001). The technician biological analyzes theoretical and practical guide. Tec and Doc. Lavoisier, Paris. 990 pp.

Bovet, P. Kizirian, N. Madeleine, G. Blössner, M. \& Chiolero, A. (2011). Prevalence of thinness in children and adolescents in the Seychelles: comparison of two international growth references. Nutrition journal, 10(1), 65.

Briend, A. (2003). Prise en charge de la malnutrition sévère de l'enfant en milieu tropical. Médecine tropicale, 63(4-5), 527-532.

Council for international organizations of medical sciences. (1982). Proposed international guidelines for biomedical research involving human subjects.

Dicksved, J., Halfvarson, J., Rosenquist, M., Järnerot, G., Tysk, C., Apajalahti, J., \& Jansson, J. K. (2008). Molecular analysis of the gut microbiota of identical twins with Crohn's disease. The ISME journal, 2(7), 716.

Diop, E. H. I., Dossou, N. I., Ndour, M. M., Briend, A., \& Wade, S. (2003). Comparison of the efficacy of a solid ready-to-use food and a liquid, milk-based diet for the rehabilitation of severely malnourished children: a randomized trial. The American journal of clinical nutrition, 78(2), 302-307.

Gobert, J-G., Barbot, L., \& Kapel, N. (2004). Elément de physiopathologie digestive et coprologie fonctionnelle. Annales pharmaceutiques françaises, 62(6), 367-370.

Gossling, J., \& Slack, J. M. (1974). Predominant gram-positive bacteria in human feces: numbers, variety, and persistence. Infection and Immunity, 9, 719-729.

Kaguamba, J. K., and Kebaabetswe, P. (2018). Rate of Weight Gain in Malnourished Children in the Malnutrition Rehabilitation Program in Bobirwa. Journal of Medicine, Nursing \& Public Health, 1(1), 24-37.

Keuleneer, F., \& Lontings, D. (1993). Privacy Protection and Personal Data Processing in Belgium: Analysis of a New Law's Centralized Approach to Regulation. International Company and Commercial Law Review, 4, 344-344.

Kolling, G., Wu, M., \& Guerrant, R-L. (2012). Enteric pathogens through life stages. Frontiers in cellular and infection microbiology, 2, 114.

Kumar, M., Ji, B., Babaei, P., Das, P., Lappa, D., Ramakrishnan, G., \& Nielsen, J. (2018). Gut microbiota dysbiosis is associated with malnutrition and reduced plasma amino acid levels: lessons from genome-scale metabolic modeling. Metabolic engineering, 49, 128-142.

Lagier, J-C., Million, M., Hugon, P., Armougom, F., \& Raoult, D. (2012). Human gut microbiota: repertoire and variations. Frontiers in cellular and infection microbiology, 2, 136.

Le Blanc, J. G., Milani, C., De Giori, G. S., Sesma, F., Van Sinderen, D., \& Ventura, M. (2013). Bacteria as vitamin suppliers to their host: a gut microbiota perspective. Current opinion in biotechnology, 24(2), 160-168.

Magnúsdóttir, S., \& Thiele, I. (2018). Modeling metabolism of the human gut 
microbiome. Current opinion in biotechnology, 51, 90-96.

Marteau, P., Pochart, P., Doré, J., Béra-Maillet, C., Bernalier, A., \& Corthier, G. (2001). Comparative study of bacterial groups within the human cecal and fecal microbiota. Applied environmental microbiology, 67(10), 4939-4942.

Million, M., Diallo, A., and Didier, R. (2017). Gut microbiota and malnutrition, Microbial Pathogenesis, 106, 127-138,

Rolland-Cachera, M-F. (1991). Méthodes d'évaluation de l'état nutritionnel chez l'enfant: application au cas particulier de l'obésité. Bulletins et Mémoires de la Société d'Anthropologie de Paris, 3(3), 191-200.

Saunders, J., Smith, T., \& Stroud, M. (2015). Malnutrition and undernutrition. Medicine, 43(2), 112-118.

Simmer, K., Khanum, S., Carlsson, L., \& Thompson, R. P. (1988). Nutritional rehabilitation in Bangladesh - the importance of zinc. The American journal of clinical nutrition, 47(6), 1036-1040.

Subramanian, S., Huq, S., Yatsunenko, T., Haque, R., Mahfuz, M., Alam, M-A., \& Barratt, M-J. (2014). Persistent gut microbiota immaturity in malnourished Bangladeshi children. Nature, 510(7505), 417.

Thompson-Chagoyán, O. C., Maldonado, J., \& Gil, A. (2007). Colonization and impact of disease and other factors on intestinal microbiota. Digestive Diseases and Sciences, 52(9), 2069-2077.

Turnbaugh, P. J., Ley, R. E., Mahowald, M. A., Magrini, V., Mardis, E. R., \& Gordon, J. I. (2006). An obesity-associated gut microbiome with increased capacity for energy harvest. Nature, 444(7122), 1027.

Waterlow, J. C., Buzina, R., Keller, W., Lane, J. M., Nichaman, M. Z., \& Tanner, J. M. (1977). The presentation and use of height and weight data for comparing the nutritional status of groups of children under the age of 10 years. Bulletin of the world Health Organization, 55(4), 489.

World Health Organization. (2000). La prise en charge de la malnutrition sévère: Manuel à l'usage des médecins et autres personnels de santé à des postes d'encadrement. https://www.who.int,nutrition,publication.

World Health Organization \& UNICEF. (2007). Prise en charge communautaire de la malnutrition aïgue sévère: déclaration commune de l'Organisation mondiale de la Santé, du Programme alimentaire mondial, du Comité permanent de la nutrition du Système des Nations Unies et du Fond des Nations Unies pour l'enfance.

World Health Organization. (2017). Formation en nutrition. Manuel du praticien Module 2: diagnostic de la malnutrition. Programe National de nutrition. Cote d'ivoire. $63 \mathrm{p}$. 